Artigo

\title{
Processos de ensino e aprendizagem em Matemática na Educação Básica: a perspectiva das aulas como experiência formativa no estágio supervisionado
}

\section{Mathematics teaching and learning processes in Basic Education: a perspective of classes as a formative experience in teaching internship}

Procesos de enseñanza y aprendizaje de las matemáticas en Educación Básica: una
perspectiva de las clases como experiencia formativa en la pasantía docente

\author{
André Pereira da Costa ${ }^{1}$ \\ (D) [0000-0003-0303-8656] \\ Anatália Dejane Silva de Oliveira² \\ (i) [0000-0003-3307-8632]
}

\section{Resumo}

O objetivo deste artigo consiste em analisar as dinâmicas de aulas de Matemática como processos de ensino e de aprendizagem no Ensino Fundamental e no Ensino Médio, durante vivências realizadas no estágio supervisionado em duas escolas públicas de um município do Oeste da Bahia. Na abordagem teórica, tecemos considerações acerca da significação dos processos de ensino e aprendizagem na constituição de relação pedagógica como ambiente relacional de buscas, trocas e partilhas. Nessa compreensão, a aula está configurada como atividade coletiva produzida conjuntamente entre alunos e professores, em situação pedagógica compartilhada no ato de conhecer a Matemática. O percurso metodológico apresenta uma abordagem qualitativa, na qual realizamos análise documental de protocolos de observação, instrumentos de registro de dados, trabalhados a partir da análise de conteúdo. No âmbito dos resultados, destacamos que nas metodologias de ensino observadas nas aulas de Matemática nos anos finais do Ensino Fundamental, bem como no Ensino Médio, há preponderância da aula expositiva, em especial, no ensino de Álgebra e de Estatística. No entanto, ressaltamos que múltiplas estratégias mobilizaram as atividades de ensino e produziram desdobramentos que diversificaram esse tipo de aula, sobretudo, no trabalho com Números. Concluímos que o estágio supervisionado consiste em espaço significativo de formação inicial de professores e de atualização profissional para quem ensina Matemática na Educação Básica, pois permite ressignificar os processos de ensino e aprendizagem sob o ponto de vista de seus estudantes.

Palavras-chave: Aulas de Matemática. Processos de ensino e aprendizagem. Educação Básica. Estágio supervisionado.

\footnotetext{
Abstract

The purpose of this article is to analyze the dynamics of mathematics classes as teaching and learning processes in elementary and high school, during experiences carried out in a teaching internship in two public schools in a municipality in the west of the State of Bahia, Brazil. In the theoretical approach, we make considerations about the meaning of the teaching and learning processes in the constitution

1 andre.costa@ufob.edu.br, Doutor em Educação Matemática e Tecnológica pela UFPE, professor, Universidade Federal do Oeste da Bahia (UFOB), Barreiras/Bahia/Brasil.

2 anatalia@ufob.edu.br, Doutora em Educação pela UFG, professora, Universidade Federal do Oeste da Bahia (UFOB), Barreiras/Bahia/Brasil.
} 
of a pedagogical relationship as a relational environment of explorations, exchanges and sharing. In this understanding, the configuration of the class took place with collective activity produced jointly between students and teachers, in a shared pedagogical situation in the act of knowing Mathematics. The methodological approach presents a qualitative approach, in which we perform a documentary analysis of observation protocols and data recording instruments based on content analysis. Within the scope of the results, we highlight that the teaching methodologies observed in mathematics classes in the final years of elementary school, as well as in high school, indicated the preponderance of lectures, especially in the teaching of algebra and statistics. However, we emphasize that multiple strategies mobilized teaching activities and produced developments that diversified this type of class, especially in working with Numbers. We conclude that the teaching internship is a significant space for initial teacher education and professional updating for those who teach Mathematics in Basic Education, as it allows the teaching and learning processes to be re-signified from the point of view of their students.

Keywords: Mathematics classes. Teaching and learning processes. Basic education. Teaching internship.

\section{Resumen}

El objetivo de este artículo fue analizar la dinámica de las clases de matemáticas como procesos de enseñanza y aprendizaje en la escuela primaria y secundaria desde la perspectiva de un estudiante graduado durante las experiencias de pasantías supervisadas, en dos escuelas públicas en un municipio de Brasil. En el enfoque teórico, hacemos consideraciones sobre el significado de los procesos de enseñanza y aprendizaje en la constitución de las relaciones pedagógicas como un entorno relacional de búsquedas, intercambios y acciones. En este entendimiento, la clase se configura como una acción colectiva producida conjuntamente por estudiantes y maestros, en una acción compartida en el acto de conocer las Matemáticas. La ruta metodológica presenta un enfoque cualitativo, en el que realizamos un análisis documental de los protocolos de observación para el estudiante de licenciatura en matemáticas, que por lo tanto consiste en instrumentos de registro de datos, trabajados desde el análisis de contenido. Dentro del alcance de los resultados, destacamos que en las metodologías de enseñanza observadas en las clases de matemáticas en los últimos años de la escuela primaria, así como en la escuela secundaria, existe una preponderancia de la clase expositiva, especialmente en la enseñanza de álgebra y estadística. Sin embargo, enfatizamos que múltiples estrategias movilizaron actividades de enseñanza y produjeron nuevos significados que diversificaron este tipo de clase, especialmente al trabajar con Números. Concluimos que la pasantía supervisada consiste en un espacio significativo para la formación inicial del profesorado y la actualización profesional para aquellos que enseñan Matemáticas en Educación Básica, ya que permite que los procesos de enseñanza y aprendizaje se vuelvan a significar desde el punto de vista de sus estudiantes.

Palabras claves: Clases de matemática. Procesos de enseñanza y aprendizaje. Educación básica. Experiencias de prácticas supervisadas.

\section{Reflexões iniciais}

Este artigo objetiva analisar as dinâmicas de aulas de Matemática como processos de ensino e de aprendizagem no Ensino Fundamental e no Ensino Médio, a partir da experiência vivenciada no estágio curricular supervisionado em duas escolas públicas de um município do Oeste da Bahia. O interesse em realizar a pesquisa derivou de nossa experiência como professores formadores do curso de licenciatura em Matemática, atuantes nas atividades de estágio curricular em uma instituição pública de ensino superior, situada no território da Bacia do Rio Grande, oeste baiano. 
O estágio curricular é campo formativo e espaço de produção de conhecimentos, onde a pesquisa assume uma função político-pedagógica em duas perspectivas. A primeira, pelo reconhecimento de nossa participação ativa e reflexiva na constituição da realidade escolar. A segunda porque se torna um instrumento de análise contextual que permite transgressões no ato de conhecer que possibilita enxergar muitas possibilidades de diálogo entre a universidade e a escola da Educação Básica, portanto, a pesquisa não se resume a uma mera atividade prática instrumental. Assim, a atividade de estágio como atitude investigativa potencializa "integrar o processo de formação do aluno, futuro profissional, de modo a considerar o campo de atuação como objeto de análise, de investigação e de interpretação crítica, a partir do nexo com as disciplinas do curso" (PIMENTA e LIMA, 2012, p. 24).

A partir do anunciado pelas autoras, reconhecemos que a docência é um espaço de investigação e produção de sentidos e significados que dá vida ao ato de conhecer, tão particular na constituição relacional dos processos de ensino e aprendizagem. Assim, a docência se faz pelo diálogo em situações de prática social, tornando o ensino uma tarefa compartilhada. Sob a responsabilidade do professor, essa tarefa é uma atividade social profunda, marcada por disputas de concepções, geralmente orientadas por diferentes princípios, posturas políticas e teórico-metodológicas na constituição da dimensão pedagógica.

Nesse contexto, dialogamos com diferentes autores para explicar que processos de ensino e aprendizagem significativos são produzidos na relação pedagógica como ambiente relacional de buscas, trocas e partilhas. Desse modo, a aula passa a ser configurada como ação coletiva produzida conjuntamente entre estudantes e professores, em ação compartilhada em torno do ato de conhecer (FREIRE, 2001, 1974; VIGOTSKI, 2007; DAVIDOV, 1998; RIOS, 1998, 2008).

Num curso de licenciatura, o estágio curricular torna-se lócus privilegiado de constituição da relação pedagógica, uma vez que é um ambiente de formação inicial para estudantes de licenciatura, e de formação continuada para professores das escolas da educação básica, tendo como articuladores dessa vivência os docentes das universidades.

A importância desse artigo para a Educação Matemática se justifica pelo reconhecimento do estágio supervisionado como espaço importante para a formação inicial de professores e de constituição da identidade profissional de quem ensina a Matemática. Ao investigar e analisar tipologias de aulas de Matemática realizadas na Educação Básica, esse texto auxiliará ao professor da escola, em formação continuada; e ao estudante de licenciatura, em formação inicial trabalharem com a complexidade dos processos de ensino e aprendizagem da Matemática como área de conhecimento e campo de atuação profissional.

Com essa organização, o presente artigo aborda avanços, contradições e possíveis embates no âmbito das atividades de ensino na escola de Educação Básica, configurando-se em uma contribuição importante ao ensino de Matemática no cenário educacional da região oeste da Bahia. Ademais, as abordagens temáticas trazidas possibilitarão a elaboração de projetos de intervenção que podem auxiliar na reflexão e compreensão dos fenômenos didáticos e pedagógicos que são objetos de interesse da Educação Matemática.

A organização do artigo apresenta, inicialmente, uma discussão conceitual acerca dos processos de ensino e aprendizagem a partir das aulas produzidas e vivenciadas na relação pedagógica por alunos e professores da Educação Básica, tomando como campo de estudo o conhecimento escolar e o ensino de Matemática no âmbito da experiência de estágio. Em 
seguida, descrevemos o itinerário metodológico da investigação. Os dados foram tratados em dois blocos temáticos. No primeiro, as experiências de alunos e professores da Educação Básica participantes das aulas de Matemática no Ensino Fundamental e no Ensino Médio, enfatizando as aulas expositivas e as expositivas dialogas como situações metodológicas que movimentaram os processos de ensino e aprendizagem. No segundo momento, tratamos do estágio supervisionado e as aprendizagens profissionais em torno do ensino da Matemática. Por fim, apresentamos as considerações finais.

\section{Os processos de ensino e aprendizagem e o sentido da aula na relação pedagógica}

Os processos de aprendizagem são plurais, dialógicos, compartilhados e, portanto, constitutivos de significados porque são produzidos em dinâmicas de sociabilidade e humanização. Essa perspectiva evidencia que na condição de seres humanos estamos constantemente produzindo relações sociais e sendo por elas produzidos, em experiências nunca repetidas, visto que são articuladas por valores e saberes significados na cultura. Parece-nos que esse é o maior desafio do trabalho escolar, sobretudo porque aprendemos muito antes de chegarmos à escola (VIGOTSKI, 2007). Ou seja, o desafio referido consiste em significar as dinâmicas de aprendizagem a partir de situações de ensino que sejam tão significativas a ponto de, indissociavelmente, constituíram-se ação formativa produzida na diversidade das relações estabelecidas entre as pessoas, configurando-se em momentos de conhecer, atribuir sentidos, produzir movimentos de saberes.

Ao se movimentar em uma dimensão política e ética, esse processo formativo requer dos profissionais da educação, a responsabilidade pedagógica de agir com o inacabado, com a promoção de mudanças, colocando os estudantes neste lugar de produção, pois são eles atores de suas aprendizagens, que agem para produzir, renovar e significar processos de busca, de inquietude e de desconstrução de verdades. Essa perspectiva de trabalho escolar dialoga com Freire (2001), quando anuncia sua atitude de professor:

[...] como professor crítico, sou um "aventureiro" responsável, predisposto à mudança, à aceitação do diferente. Nada do que experimentei em minha atividade docente deve necessariamente repetir-se. Repito, porém, como inevitável, a franquia de mim mesmo, radical, diante dos outros e do mundo. Minha franquia ante os outros e o mundo mesmo é a maneira radical como me experimento enquanto ser cultural, histórico, inacabado e consciente do inacabamento (FREIRE, 2001, P. 55).

Na constituição desse processo, torna-se importante que a postura do professor se desloque 'do lugar de quem sabe tudo' para o 'lugar da troca, da partilha e da ação conjunta de significados'. Por isso, é preciso superar a visão iluminista de escola como aquele espaçotempo, em que se ensina a quem nada sabe, fenômeno denominado por ele como educação bancária (FREIRE, 2001). Ao contrário disso, é preciso reconhecer que o trabalho do professor junto aos estudantes faz da escola um ambiente de produção cultural, potencializador de ações que podem desconstruir verdades convencionadas pela ciência positivista, por exemplo, romper com lógica do conhecimento 'verdadeiro' ser aquele que a escola transmite, porque em algum momento foi validado como importante e útil para interesses determinados pela organização econômica da sociedade moderna. Nesse circuito, à escola tem-se delegado a responsabilidade de se apropriar dessas 'verdades', entre outras questões, definindo no campo do currículo escolar, o que vale a pena ser ensinado para essa sociedade. 
A mudança de perspectiva contrária aos princípios da ciência moderna combinada com a concepção da educação como sociabilidade e humanização, coloca-nos em diálogo com outras possibilidades de significar o trabalho formativo da escola. Para nós, uma das mais relevantes atitudes consiste em reconhecer as experiências produzidas pelos processos de ensino e aprendizagem como mobilizadores das relações de trocas, partilhas e significações. Assim, cabe-nos destacar que "[...] a escola deve ensinar os alunos a pensar, quer dizer, desenvolver ativamente neles os fundamentos do pensamento contemporâneo para o qual é necessário organizar um ensino que impulsione o desenvolvimento" (DAVIDOV, 1998, p. 3).

Sob essa compreensão, a escola se ocupa em produzir interrelações provocadas pelos estudantes, engajados nos processos da convivência diária, significados pelas permanentes ações de buscas, trocas e partilhas, fazendo surgir situações diversas de ensino a partir de uma relação pedagógica contextualizada. Isto significa dizer que a aprendizagem não depende do ensino, porque ele não pode anunciar algo que é experiencial, ou seja, aprendizagem é construto relacional. Por isso, o ensino é atividade promotora do buscar, trocar e partilhar sentidos e significados entre saberes, mediado por ações intencionadas na ambiência escolar no ato de conhecer. Por isso, essa dinâmica movimentada pelas próprias convivências materializadas na e pela diversidade em situações sociais de desenvolvimento.

Assim, a aprendizagem "ativa todo um grupo de processos de desenvolvimento, e esta ativação não poderia produzir-se sem a aprendizagem" (VIGOTSKI, 2001, p. 115). Essa afirmativa é importante para enfatizarmos que só faz sentido abordar a concepção de ensino na educação escolar, se este estiver vinculado à complexidade do desenvolvimento humano, que se faz em uma ambiência relacional, dentro e fora da escola, produzindo sentidos e significados pela ação dos sujeitos engajados no ato de conhecer.

O ensino nesse contexto pode ser relacionado ao ato de buscar e dar sentido ao que se faz na escola é um caminhar constante, pois "se o saber pretendido é um saber inteiro, fazse necessária uma atitude de admiração diante do conhecido, de surpresa diante do habitual, a fim de conhecer mais e melhor" (RIOS, 1998, p. 96). Para tanto, a aula toma a dimensão ética como articuladora das dimensões política, estética e técnica que organizam os processos de ensino e aprendizagem, de forma que ela se torna experiência de busca, troca e partilha.

[...] uma aula não é algo que se dá, mas algo que se faz, ou melhor, que professores e alunos fazem, juntos. Afirmar que fazem juntos não significa, absolutamente, dizer que fazem de maneira igual. É na diferença e na reciprocidade de papéis que vai se constituindo o evento que se chama aula (RIOS, 2008, p. 75).

A aula, portanto, faz parte da simbologia que organiza a complexidade da diversidade do trabalho escolar. No entanto, a responsabilidade educativa da escola é compartilhada com a sociedade pelo trabalho formativo que ambas realizam. Essa é uma questão muito significativa, pois se entendemos que a aula não se dá, mas se faz com o outro de forma colaborativa, então o conhecimento pode fazer parte das experiências do estudante. Essa visão de aula como uma dinâmica permanente de constituição relacional, provoca uma mudança nas maneiras pelas quais os processos de ensino e aprendizagem têm se colocado historicamente no trabalho da escola.

Reiteramos que essa concepção de aula qualifica a relação pedagógica, fortalecendoa para provocar rupturas nos rituais escolares, produzidos pela lógica da educação como 
serviço. Nesse modelo educacional, a aula compreende um tempo cronometrado pelo relógio no espaço escolar, dentro do qual precisa ser colocado um determinado conhecimento válido/útil, geralmente abordado na lógica iluminista de transmissão do professor para o estudante, muitas vezes, a partir da indicação do livro didático.

Diferentemente, na perspectiva da relação pedagógica produzida entre professores e estudantes, a aula se faz em partilha, promovendo o ato de conhecer. A aula é, portanto, ambiente relacional, permanentemente, instigado pela ação dos sujeitos comprometidos com os processos de ensino e aprendizagem. Do ponto de vista da aprendizagem e do desenvolvimento humano, tal fenômeno é muito importante porque não se limita a simples apropriação do conhecimento em si. Nesse cenário, chamamos conhecimento em si àquele que está fora do sujeito, distante de sua realidade social e que, por ser algo pronto e previamente delimitado, tem-se a ideia de que pode ser transmitido.

\section{Conhecimento escolar e o ensino de Matemática na experiência de estágio}

Esse conhecimento é, geralmente, organizado no currículo da escola a partir de áreas de conhecimentos específicas, trabalhadas em momentos formativos que articulam saberes e experiências de estudantes e professores. É um trabalho que faz da escola um lugar onde se articulam informações conhecidas e desconhecidas, realidades próximas e longínquas. São diálogos em torno de diferentes e ampliadas questões e relações, anunciadas pela percepção de mundo vivenciada na escola pelos estudantes, que compõem a longa trajetória escolar de uma pessoa.

Nessa trajetória, as áreas de conhecimento são agrupadas e distribuídas em componentes curriculares, nomeados e disciplinados para reservarem aos estudantes um conjunto de saberes específicos. Esses saberes são organizados de modo a compor todo o processo de escolarização, sendo trabalhados em aulas que os materializam, geralmente, potencializadas por determinados ritos nas atividades de ensino.

Uma das áreas do conhecimento escolar é a Matemática, socialmente, considerada saber essencial para a formação de sujeitos, formalizada como uma disciplina universal. Essa natureza universal coloca a Matemática no trabalho da escola de forma "descontextualizada, com 'verdades eternas', obtidas pelo poder da lógica, lidando com um conjunto articulado de conceitos abstratos" (LIMA BORBA; PEREIRA DA COSTA, 2018, p. 57). Tal concepção tem gerado embates e rupturas nos processos de ensino e aprendizagem, inclusive, possibilitando a (re)significação da relação pedagógica entre estudantes e professores diante do ato de conhecer a Matemática, na perspectiva de uma ciência humana e viva.

Em variados contextos escolares, as aulas de Matemática têm sido organizadas e desenvolvidas ainda com base em princípios da escola iluminista, por meio dos quais o professor é quem detém o saber, utilizando-se da exposição oral com apoio do registro no quadro de giz como recurso pedagógico privilegiado do trabalho docente, em um ritual permanente de 'aplicação' de exercícios, muitas vezes, desarticulados da realidade social. Nesse cenário, os estudantes se mostram desmobilizados nos processos de aprendizagem como ambientes relacionais de busca, troca e partilha de saberes e significações, apresentando baixos níveis de participação e, consequentemente, produzindo desempenhos aquém do esperado. Em situação de aula, colocam-se ou são colocados como copistas, registrando no caderno o que é apresentado pelo professor. Essa perspectiva reafirma a 
compreensão de que a aula é algo que se faz, exclusivamente, pelo professor, sem a participação colaborativa do estudante (RIOS, 2008).

A Educação Matemática como conhecimento científico, é também campo de formação e de atuação profissional. Uma das ocupações profissionais de maior destaque refere-se ao magistério. Nesse contexto, ganha força e papel importante a formação inicial de professores(as), visto que ela se preocupa em produzir "conhecimentos e práticas pedagógicas que contribuem para uma formação mais integral, humana e crítica" (FIORENTINI; LORENZATO, 2012, p. 4) dos sujeitos envolvidos na relação pedagógica.

A licenciatura em Matemática assume uma responsabilidade social nesse processo porque se ocupa da formação de professores para a Educação Básica e o Ensino Superior. 0 propósito de se criar processos de aprendizagem profissional nesta licenciatura, potencializa a apropriação da Matemática como conhecimento necessário para analisar e compreender situações complexas da sociedade, mostrando caminhos adequados para superá-las a partir de uma formação intelectual e social que precisa compor a trajetória acadêmica de estudantes que buscam a docência como profissão.

Nesse âmbito, a identidade profissional é processo complexo, dinâmico, temporal e influenciado por nossas experiências (CYRINO, 2017). As interfaces desses saberes acontecem pela articulação entre a escola de Educação Básica e a Universidade, lócus privilegiado de formação de professores(as). Nos cursos de licenciatura, o estágio supervisionado assume essa mediação com papel importante na constituição da identidade do professor que ensina a Matemática. No estágio o estudante de licenciatura aprofunda sua relação com a escola, ambiente de exercício da profissão docente, espaço privilegiado de produção de conhecimentos e saberes, de socialização e formação de pessoas. É neste lugar onde as crenças/concepções, o autoconhecimento, o conhecimento da profissão, a autonomia e o compromisso político são modificados e (re)significados. Dimensões essas que influenciam os processos de constituição da identidade profissional do professor que ensina a Matemática.

A partir desses pressupostos, o exercício da profissão docente na área de Matemática exige reconhecer o professor como ator responsável pela produção e (re)significação de conhecimentos e práticas pedagógicas que possibilitem uma formação intelectual e social dos estudantes, numa perspectiva integral, integrada, política e crítica dos alunos. Isso é possível a partir da concepção de Matemática como ciência social, humana e dinâmica, amparada em um projeto de educação pela Matemática e não para a Matemática.

Nesse cenário, o estágio supervisionado é um dos espaços formativos que a Matemática utiliza para a compreensão e o estudo aprofundado da sociedade na complexidade da educação escolar. É instrumento teórico-epistemológico importante de formação acadêmico-profissional, que promove aprendizagens contextualizadas pela Matemática. Essa concepção de estágio supervisionado fortalece o entendimento e o reconhecimento da Matemática como ciência humana e viva (D'AMBROSIO, 2016).

Esse processo de vivência compartilhada do estudante de licenciatura na escola de Educação Básica e no curso de Matemática, reforça o papel político, ético e social do estágio supervisionado como 'termômetro formativo' que produz sentidos e significados para a identificação ou não com a profissão docente. Do mesmo modo, valoriza a Educação Matemática na formação inicial e continuada de professores como área de conhecimento que busca a ressignificação dos processos de ensino e aprendizagem exercitados, cotidianamente, nas relações pedagógicas da educação escolar. 


\section{Itinerário metodológico da investigação}

Nesta pesquisa trabalhamos com a abordagem qualitativa (BORBA; ARAÚJO, 2010), visto que oferece elementos para analisar os processos de ensino e aprendizagem realizados nas aulas de Matemática na Educação Básica, a partir de experiências registradas em atividades de estágio supervisionado no curso de licenciatura em Matemática.

Essa abordagem de investigação no campo da Educação Matemática se realizou por meio de estudo de caso do tipo etnográfico, "por possibilitar condições de aprofundamento de uma realidade (...), em que a fala do outro deve ser interpretada dentro do seu sistema de referências, será a sua experiência de vida que dará o significado e o sentido à sua fala" (LARCHERT, 2017, p. 126-127). Sob esse pressuposto de pesquisa, explicaremos as tipologias das aulas de Matemática vivenciadas no âmbito de duas etapas da Educação Básica.

Para tanto, o contexto da pesquisa foram duas escolas públicas localizadas no município de Barreiras-BA, localizado a $910 \mathrm{~km}$ da capital do estado, sendo uma que oferta exclusivamente os anos finais do Ensino Fundamental, vinculada ao sistema municipal de ensino; a outra oferece o Ensino Médio, pertencente ao sistema estadual de educação. Os participantes que colaboraram na realização da investigação foram: 02 professoresformadores e um estudante do curso de licenciatura em Matemática da Universidade; 241 alunos e 05 professores da Educação Básica. O quantitativo do corpo estudantil frequente durante o período de observação, é majoritariamente, formado pelo sexo feminino, correspondente a 56,81\% e 43,19\% masculino.

Os procedimentos da pesquisa se operacionalizaram por meio de uma experiência de investigação em vivências de estágio supervisionado. $O$ caso em estudo compreende a proposta de estágio do curso de licenciatura em Matemática organizado em quatro semestres. Nos dois primeiros, os estudantes vivenciam experiências formativas de observação na dinâmica dos processos de ensino e aprendizagem das aulas de Matemática na escola dos anos finais do Ensino Fundamental e no Ensino Médio, respectivamente. Nos dois últimos semestres de estágio, eles já se ocupam das atividades de iniciação à docência, nestas etapas da Educação Básica. Assim sendo, essa investigação apreende os dois primeiros semestres da proposta curricular do estágio supervisionado.

Durante o período de observação, os estudantes da licenciatura em Matemática trabalharam com protocolos de pesquisa como instrumento de levantamento de dados, contendo itens previamente definidos. O primeiro constituiu em dados de identificação da escola, do professor e dos alunos. O segundo item, orienta a descrição literal de como as aulas de Matemática foram realizadas a partir das relações estabelecidas entre professores e alunos, bem como dos alunos entre si. Já o terceiro, registravam-se dúvidas e questionamentos do estudante de licenciatura em relação ao que vivenciou na aula e, por fim, último item, indicavam-se as preocupações que o professor manifestou durante a aula, notadamente, com foco na aprendizagem matemática dos alunos.

Os protocolos foram preenchidos, semanalmente, pelo estudante de licenciatura em Matemática durante suas vivências no estágio curricular supervisionado, ao longo de dois semestres, totalizando doze (12) protocolos em 20 horas de observação. Especificamente, nos anos finais do Ensino Fundamental as observações aconteceram em 06 (seis) turmas distribuídas entre dois professores e, no segundo semestre no Ensino Médio, em 05 (cinco) turmas com três professores diferentes, todos com formação em licenciatura ou curso de 
complementação pedagógica em Matemática. Nas onze (11) turmas participaram 241 alunos da Educação Básica.

Ao tomar os protocolos como instrumento de pesquisa neste estudo no campo da Educação Matemática, eles se constituem relevantes e singulares documentos que registram as informações advindas das situações de ensino e aprendizagem nas aulas de Matemáticas realizadas na Educação Básica em escolas públicas da região oeste da Bahia. Trata-se, portanto, de documentos analisados mediante tratamento científico. Assim, reconhecemos a análise de documentos como referência que qualifica a investigação científica, por interessar no estudo de documentos que não foram considerados em outras pesquisas, ou então, ainda não tratados de forma analítica (GIL, 2008).

Quanto à organização e intepretação dos dados advindos dos protocolos, trabalhamos com a análise de conteúdo (BARDIN, 2010), a partir do mapeamento das informações para a obtenção de uma visão geral dos processos de ensino e aprendizagem realizados em aulas de Matemática; da construção de categorias de análise e sua compilação no conjunto dos dados; da condensação e definição das categorias que a serem enfatizadas no estudo, quais sejam: processos de ensino e aprendizagem em Matemática, aulas expositivas, aulas expositivas dialogadas e estágio supervisionado.

\section{As experiências de alunos e professores da Educação Básica sobre as aulas de Matemática}

A aula coloca a relação didático-pedagógica entre alunos e professores em ação. No caso da Matemática, as aulas se constituem momentos de produção, significação e consolidação de conhecimentos matemáticos necessários à formação integral e integrada do aluno. Mas, para isso acontecer de forma significativa, é necessário que o ensino de Matemática seja conduzido de maneira que possibilite a reflexão sobre problemas e situações que lhes são propostas a partir das realidades vividas, envolvendo-se nesse saber de forma prazerosa e contextualizada.

A Educação Matemática tem o desafio de conquistar o aluno da Educação Básica pelo envolvimento no protagonismo de sua aprendizagem, ajudando-o perceber que a Matemática é uma ciência dinâmica que possibilita e oportuniza criticidade, criatividade e afetividade. No entanto, uma das questões apreendidas na investigação consistiu na identificação entre os 241 alunos (124 do Ensino Fundamental e 117 do Ensino Médio), manifestando-se acerca de gostar ou não de estudar Matemática. Os dados estão no quadro 01, a seguir.

Quadro 01: Manifestação dos alunos sobre as aulas de Matemática

\begin{tabular}{|l|c|c|}
\hline Etapa da Educação Básica & \% Gostam & \% Não Gostam \\
\hline Ensino Fundamental & $33,06 \%$ & $66,94 \%$ \\
\hline Ensino Médio & $52,42 \%$ & $41,94 \%$ \\
\hline
\end{tabular}

Fonte: Elaborado pelos autores

$\mathrm{Na}$ análise dos dados, observamos que os alunos que manifestaram não gostar de estudar de Matemática tem percentual maior no Ensino Fundamental $(66,94 \%)$ do que os do Ensino Médio (41,94\%). Os dados da investigação evidenciaram que as aulas de Matemática para o primeiro grupo aconteceram desarticuladas da realidade social e, portanto, divorciadas dos interesses e demandas dos alunos. Se entendemos que motivação para estudar significa ter motivos para uma ação, nessa direção, a demonstração dos alunos em não participar das 
aulas e atividades propostas pelo professor, demonstra que elas não se constituíram em momentos de produção e significação de conhecimentos matemáticos.

Durante as aulas, os alunos desta etapa da Educação Básica eram colocados para responder uma lista de exercícios infindáveis, sem contextualização e sem sentido para eles, gerando uma "pseudo aprendizagem" sob uma perspectiva baldista que, segundo Câmara dos Santos (2002) é um novo conceito matemático, em que o aluno é considerado um "balde vazio", que será "enchido" pelo professor. Nessa situação pedagógica, o protagonismo é do docente, uma vez que o aluno se coloca na relação pedagógica como um sujeito passivo, em que o erro, por exemplo, deve ser evitado, pois a avaliação é classificatória e de medida.

Essa mesma situação foi evidenciada no Ensino Médio, com dimensão mais amena, pois embora os estudantes observaram que, muitas vezes, não há conexão entre o que é trabalhado na escola e a vida que corre fora de seus muros, eles conseguem acompanhar as aulas dos professores em função da metodologia de ensino adotada.

Do total de alunos de ambas as etapas da Educação Básica que manifestaram não gostar de Matemática, suas atitudes nas aulas demonstraram algumas razões que ilustram o não envolvimento nas relações pedagógicas para a apropriação de conhecimentos matemáticos. Do total de sinalizações apontadas nos protocolos, temos o seguinte.

Quadro 02: Atitudes dos alunos nas aulas de Matemática

\begin{tabular}{|l|c|}
\hline \multicolumn{1}{|c|}{ Situações identificadas } & $\%$ \\
\hline Se envolvem em conversas paralelas durante toda a aula & $36,84 \%$ \\
\hline Demonstram não se interessar pela aula, saindo da sala o tempo todo & $26,32 \%$ \\
\hline Em silêncio, copiam no caderno os registros do quadro & $21,05 \%$ \\
\hline Observam a aula e não fazem qualquer registro & $15,79 \%$ \\
\hline
\end{tabular}

Fonte: Elaborado pelos autores

Os dados sinalizam um mesmo movimento entre os alunos do Ensino Fundamental e os do Ensino Médio para a forma como os conteúdos de Matemática são abordados nos processos de ensino e aprendizagem. Enquanto os primeiros expressam que não conseguem enxergar motivos para estudar Matemática, os outros apontam que não veem sentido em alguns conteúdos matemáticos, pois não os utilizarão em sua vida.

Na perspectiva dos professores participantes do estudo, há uma preocupação comum entre eles que consiste na não aprendizagem dos conteúdos de Matemática pelos alunos. Além de reconhecerem que não possuem as condições de trabalho necessárias para a realização das atividades de ensino, sinalizaram que o não envolvimento dos alunos nas aulas, deve-se também por alguns motivos, conforme explicitado no quadro 03, a seguir.

Quadro 03: Hipóteses dos professores sobre a não aprendizagem dos alunos

\begin{tabular}{|l|c|}
\hline \multicolumn{1}{|c|}{ Itens } & $\%$ \\
\hline Apresentam dificuldades em acompanhar o conteúdo de Matemática & $36,36 \%$ \\
\hline Não demonstram interesse em aprender a Matemática & $45,45 \%$ \\
\hline Não gostam de estudar & $18,18 \%$ \\
\hline
\end{tabular}

Fonte: Elaborado pelos autores

Os dados mostram que tanto no Ensino Fundamental como no Ensino Médio, a não participação dos estudantes nos processos de ensino e aprendizagem foi apontada pelos professores como algo próprio e exclusivo dos alunos. Essa compreensão isolada de seu contexto político-pedagógico pode desqualificar outros fatores responsáveis pela criação de 
um ambiente escolar relacional favorável ao engajamento dos alunos com o conhecimento matemático.

As justificativas apresentadas isolam os estudantes de uma relação dialógica com o professor, ou seja, há uma tendência negacionista de colocá-los em situações de diálogos, trocas, buscas e compartilhamentos. As narrativas evidenciam um movimento de culpabilização dos estudantes pelas não aprendizagens, o que pode resultar no imaginário escolar e familiar que eles são os responsáveis pelo fracasso escolar com a Matemática e, consequentemente em uma escala maior, pela evasão escolar.

Ao considerar que o conhecimento matemático é uma construção oriunda de um processo histórico, as dinâmicas de ensino e aprendizagem na escola precisam acontecer em condições favoráveis com recursos didáticos-pedagógicos que valorizem essa ciência como plural, coletiva e compartilhada entre alunos e professores. Assim, as aulas de Matemática podem ser organizadas de forma que o aluno tenha o protagonismo na dinâmica social de sua aprendizagem, sendo sujeito ativo que dialoga com o professor, este um parceiro em sua trajetória escolar.

Nesse contexto dual de percepção das aulas de Matemática entre alunos e professores, um aspecto importante se refere às limitadas condições de trabalho disponibilizadas nas escolas. Além de não contar com recursos didáticos específicos para o ensino da Matemática, as salas não tinham a climatização adequada para uma região de clima seco com alta temperatura, durante praticamente o ano letivo inteiro, motivo de reclamação dos estudantes.

Nesse contexto, os dados da investigação sinalizam que a Matemática está sendo trabalhada em uma perspectiva de ensino depositário, no qual o professor acredita que, ao depositar de maneira linear e abstrata as informações, o aluno se colocará como armazenador. Esse modo de pensar reforça a ideia de que a escola trabalha com a concepção de um tipo de conhecimento que somente será útil no futuro. Os dados nos mostram, ainda, que essa compreensão de aula como preparação para o futuro existe somente no imaginário da educação escolar, visto que os alunos demonstram outro querer, pois se colocam como sujeitos disponíveis para vivenciar as situações do tempo presente. É desse lugar que eles se mobilizam para participar das aulas quando contextualizadas, cujas atividades formativas são pautadas por buscas, trocas e partilhas de saberes, tomando como referência a realidade social, ou seja, suas experiências de vida.

Os dados sinalizam ainda uma característica recorrente entre as 11 turmas observadas, sendo que em 7 (sete) delas, a maioria dos alunos se sentava ao fundo da sala de aula, dividindo-se em grupos diferentes tematizados por disputas de territórios entre eles. Em todas as turmas com esta realidade, os professores se mostravam muito incomodados, permanentemente, solicitando atenção e silêncio. Enquanto isso, os demais colegas que se sentavam em frente à mesa do professor, não se envolviam nas conversas, dedicando-se às atividades.

Quando o ensino de Matemática não é conduzido de forma que os alunos participem ativamente das aulas junto com o professor, eles demonstram não sentir necessidade de se envolverem/engajarem nas propostas de ensino em aula. Do contrário, quando a ação é conjunta e compartilhada entre estes sujeitos, eles produzem uma relação pedagógica comprometida com a aprendizagem, uma vez que as interações ali constituídas atribuem sentidos e significados ao ato de conhecer a Matemática. 
Sob essas condições, as metodologias de ensino vivenciadas pelos alunos da Educação Básica nas aulas abordaram três campos da Matemática, especificamente: Números, Álgebra e Estatística, a partir de três tipos de aulas, conforme quadro 04, a seguir.

Quadro 04 - Metodologias de ensino nas aulas de Matemática

\begin{tabular}{|c|c|c|c|c|}
\hline \multirow{2}{*}{$\begin{array}{c}\text { Etapa da } \\
\text { Educação Básica }\end{array}$} & \multirow{2}{*}{$\begin{array}{l}\text { Metodologias } \\
\text { de ensino }\end{array}$} & \multirow[b]{2}{*}{$\%$} & \multicolumn{2}{|l|}{ Temáticas trabalhadas } \\
\hline & & & Conteúdos & $\begin{array}{l}\text { Campos da } \\
\text { Matemática }\end{array}$ \\
\hline \multirow{4}{*}{$\begin{array}{l}\text { Ensino } \\
\text { Fundamental }\end{array}$} & $\begin{array}{l}\text { Aula expositiva } \\
\text { dialógica }\end{array}$ & $16,67 \%$ & Expressões numéricas & Números \\
\hline & \multirow{3}{*}{ Aula expositiva } & \multirow{3}{*}{$83,83 \%$} & Equação polinomial do 1o grau & \multirow{3}{*}{ Álgebra } \\
\hline & & & Equação polinomial do 10 e $2 \circ$ graus & \\
\hline & & & Equação polinomial do $2^{\circ}$ grau & \\
\hline \multirow{3}{*}{ Ensino Médio } & $\begin{array}{l}\text { Aula expositiva } \\
\text { dialógica }\end{array}$ & $33,33 \%$ & Operações com conjuntos numéricos & Números \\
\hline & \multirow{2}{*}{ Aula expositiva } & \multirow{2}{*}{$66,67 \%$} & Razão e proporção & Álgebra \\
\hline & & & $\begin{array}{l}\text { Média aritmética, moda, mediana e } \\
\text { média ponderada }\end{array}$ & Estatística \\
\hline
\end{tabular}

Fonte: Elaborado pelos autores

Nas metodologias de ensino observadas nas aulas de Matemática nas duas etapas da Educação Básica, identificamos a preponderância da aula expositiva, 83,83\% no Ensino Fundamental e $66,67 \%$ no Ensino Médio. No entanto, outras estratégias metodológicas mobilizaram as ações de ensino, diversificaram o tipo de aula expositiva somente pela exposição oral do professor para outra dinâmica de expositiva, aquela que promove interação e envolvimento dos alunos, denominada aqui de expositiva dialogada. Em ambas as etapas, 90,90\% das utilizaram como recursos didáticos o livro didático, o quadro de giz e o caderno dos alunos, enquanto $9,10 \%$ projetor de slides.

Preliminarmente, ressaltamos que a aula expositiva é caracterizada pela centralidade do professor na condução dos processos de ensino, mediante exposição oral de determinado conteúdo, com ou sem registro no quadro. Esse é o modelo clássico de aula na tendência pedagógica que fundamenta a educação tradicional, na qual não há envolvimento relacional do aluno, que é colocado na condição de copista, seja das ideias ou dos registros apresentados pelo professor. Este é o tipo de aula denominada de educação bancária (FREIRE, 1979).

Os dados nos mostram que tanto no Ensino Fundamental como no Ensino Médio, as aulas de Álgebra se concentraram como expositivas, nas quais o professor resolve e corrige itens do livro didático no quadro de giz e os alunos o acompanham, fazendo os registros no 
caderno. O ensino da Álgebra está sendo utilizado como solo fértil para esse tipo de metodologia com o estudo de equações polinomiais do primeiro e segundo graus, e de razão e proporção. É um tipo de aula que pode levar os alunos da Educação Básica a compreenderem que conceitos algébricos se aprendem com longas listas de exercícios para resolver por meio da memorização. A Álgebra está sendo explorada de forma descontextualizada da realidade social do aluno, que não percebe relação com sua prática social. Do modo como está sendo trabalhada em aula não produz sentidos e significados que promovam aprendizagens, caracterizando esse campo matemático como algo abstrato e distante de sua vida cotidiana.

A esse respeito, o ensino de Álgebra na Educação Básica deve "ocorrer com foco no desenvolvimento do pensamento algébrico, em que os objetos algébricos e a linguagem utilizada para representá-los devam ser aprendidos pelos alunos de forma significativa" (ALMEIDA, 2017, p. 1). Em nossa opinião, uma sugestão possível para o ensino de Álgebra é envolver os alunos em uma discussão sobre conceitos algébricos a partir de fatos, vivências e experiências da realidade social apresentada por eles, contextualizando e problematizando a Álgebra aos conhecimentos da realidade em que vivem. Nesse diálogo, questões emergem do contexto de vida dos alunos, e o professor terá à sua disposição um conjunto de elementos simbólicos para trabalhar pensamento e linguagens algébricas em situações significativas em que os alunos se sentem motivados a utilizar esse conhecimento matemático.

Observamos que no Ensino Médio a Estatística foi trabalhada em aulas expositivas, semelhantes ao acontecido com a Álgebra. Preocupa-nos que o conhecimento estatístico, que possui ampla articulação com as práticas sociais e tem uma função essencial à vida em sociedade, não esteja assim compreendido pelos alunos da Educação Básica. Uma abordagem metodológica para este campo matemático, pode ser enriquecida pela relação estabelecida com o seu uso nos meios de comunicação.

Atualmente, as tecnologias de comunicação e informação têm relativo alcance entre os alunos, sobretudo a partir da experiência vivenciada no ensino remoto em tempos da pandemia da Covid-19, logo, o ensino de Estatística deve priorizar tratamento de dados em torno de problemas sociais, políticos, ambientais e sanitários, potencializando filtros de informações confiáveis. Assim, esse campo tem múltiplas possibilidades para ser tratado no ambiente das demandas sociais, tornando-se uma importante ferramenta de análise, modelagem e solução de problemas em nível local, regional, nacional e mundial. Nessa direção, Estatística e Probabilidade precisam ser contextualizadas com propostas de atividades de ensino que valorizem a produção de pesquisas e organização dos dados pelos alunos. Neste processo formativo, promove-se o desenvolvimento da autonomia e senso crítico.

Destacamos que nestas aulas expositivas no ensino de Matemática houve pouca participação dos alunos, conforme registrado em protocolo da pesquisa:

Apesar da insistência dos professores em perguntar sobre a temática abordada na aula, alguns alunos ouviam e permaneciam em silêncio, outros se envolviam em diálogos sobre outros assuntos e resistiam em copiar no caderno os registros que os professores faziam no quadro de giz. Estas situações deixavam os professores inquietos, que ficavam muito tempo da aula pedindo silêncio e atenção dos alunos à sua exposição. Outras vezes, eles iam até os alunos que se encontravam em grupos de conversas paralelas para afastá-los. Nessa dinâmica, os alunos que mais se manifestavam na aula em relação ao assunto de Matemática estavam 
sempre sentados em frente à mesa do professor. Ademais, os alunos se dispersavam muito facilmente durante a exposição e não manifestavam interesse em dialogar com o professor. Apesar disso, transcreviam no caderno toda a atividade registrada no quadro de giz (ESTRATO DO PROTOCOLO DO ESTAGIÁRIO, 2018).

Neste tipo de aula expositiva, não há espaço para questionamentos pelos alunos que se veem obrigados a memorizar o conteúdo abordado na aula, na expectativa de reproduzi-lo em exercícios que, posteriormente, são validados ou não em determinado tipo de exame. Os dados evidenciam que as atividades propostas no ensino de Matemática são caracterizadas por listas de exercícios, desarticulados da realidade social e, desse modo, sem significado para os alunos. Parece-nos que, neste modelo, as aulas de Matemática estão presas no tempo cronometrado pelo relógio, pois o propósito das atividades é manter os alunos ocupados até acabar o período da aula. Essa concepção vivenciada repetidamente nas experiências escolares, reforça nos alunos a ideia de que a Matemática se resume, abstratamente, aos cálculos e números, simplificando, portanto, o ato de conhecer o saber matemático.

Aulas neste formato de exposição sem participação dos alunos, inibem a constituição de uma relação pedagógica que promove a articulação entre os processos de ensino e as situações de aprendizagem. Nestas condições, a memorização é o único recurso que o aluno lança mão para a realização das atividades. Entre as 11 turmas observadas, houve pouca participação dos alunos nas aulas, bem como um nível baixo entre quem realizava as atividades encaminhadas para casa. Do total de 241 alunos, 72,73\% não faziam as atividades de casa, e 27,27\% apresentavam aos professores suas produções.

Ademais, nas aulas de algumas turmas havia uma abertura para os alunos interpelarem e dialogarem com o professor sobre o conteúdo que estava sendo trabalhado. A esta situação denominamos aula expositiva dialogada, pois ao fazer perguntas durante a exposição do professor, o aluno cria possibilidades de conversação, trocas e partilhas na convivência em sala. Ao criar situações que abordam a realidade social, eles próprios estabelecem uma relação pedagógica que potencializa empolgantes diálogos.

Essa perspectiva de aula é mais comunicativa, os alunos se relacionam com o professor em torno de atividades de resolução de problemas, trocando informações na busca de respostas, compartilhando experiências de aprendizagem (VIGOTSKI, 2001). Essa situação social de desenvolvimento, o diálogo é inseparável da reflexão e da ação, orientando alunos e professor para a questão que está sendo conhecida e apropriada (FREIRE, 1979). Esse contexto formativo foi identificado em $16,67 \%$ das turmas do Ensino Fundamental e em $33,33 \%$ do Ensino Médio. Nessas aulas, os alunos se mostravam mais participativos, fazendo questionamentos, ainda que naquele momento, a maioria deles não conseguisse resolver os exercícios propostos, interagiam com o professor buscando informações para respondê-los, demonstrando interesse pelas situações problematizadas.

Nas aulas expositivas dialogadas destaca-se o trabalho com Números. Nestas aulas houve diálogos e trocas entre os participantes durante os processos de ensino e aprendizagem. Em um ambiente dialógico, os alunos conseguem, por si próprios, estabelecer relações de partilha de experiências com os campos da Matemática, uma vez que esses saberes se articulam diretamente com sua realidade social. Os dados indicam que no ensino de Números, os alunos demonstraram se sentir à vontade para a socialização de suas experiências, utilizando a linguagem numérica, com maior envolvimento e participação nas 
aulas, protagonizando empolgantes diálogos e trocas entre eles e seus professores, constituindo, portanto, uma relação pedagógica interativa, dialógica.

O trabalho com Números se inseriu de forma significativa no universo social dos alunos e, por isso, houve mobilidade de saberes nos processos de ensino e aprendizagem. Nestas turmas, observamos que os alunos interagiam de forma dialógica com os professores, fazendo escolhas e partilhas nas atividades realizadas. Nas aulas havia pouca conversa paralela, pois a maioria dos alunos estava engajada nas atividades vivenciadas no coletivo, participando na elaboração e apresentação de hipóteses para a temática trabalhada pelos professores. Nesse ambiente eles manifestavam, espontaneamente, os mais diversos questionamentos em torno do conhecimento matemático que estava sendo aprendido.

Os professores que promovem trocas e diálogos com os estudantes em aulas expositivas dialógicas, percebem que estes fatores podem contribuir para o envolvimento dos estudantes. Estes profissionais veem a contextualização e a problematização como experiências significativas capazes de promover a superação das dificuldades enfrentadas pelos estudantes, que se mostraram empolgados e se interessaram em buscar, trocar e partilhar o ato de conhecer a Matemática.

Nos processos de ensino e aprendizagem, a Matemática só será considerada humana e viva, se os alunos participarem ativamente da aula, a partir de suas experiências, elaborando hipóteses e conjecturas, produzindo sentidos ao ato de (re)conhecer o saber matemático. Do contrário, se na escola os alunos não participarem do fazer aula (RIOS, 2008), reforça-se entre eles, o entendimento de que a Matemática se resume a números e cálculos, descaracterizando os contextos de onde emergem o conhecimento matemático como uma atividade humana. A escola pública do século XXI que não acolhe essa concepção de ensino, trabalha na superação de fronteiras, produzindo novos paradigmas sociais, colocando o seu trabalho na linha de frente para romper, junto aos jovens e adolescentes, concepções sociais iluministas e percepções educacionais tecnicistas (FIORENTINI; LORENZATO, 2012; D'AMBROSIO, 2016).

No âmbito da Matemática, tal fato pode representar uma grande revolução, tendo em vista que o ensino dessa área foi (e ainda é, em certos casos) marcado por um conservadorismo pedagógico, que tem gerado, por exemplo, implicações negacionistas para a Educação Matemática como campo de formação e atuação profissional que mobiliza os processos de conhecer a Matemática tanto na Educação Básica como na Educação Superior. A partir do trabalho dos cursos de licenciatura em Matemática, esse entendimento tem chegado com muita força nas escolas, ressignificando os processos de ensino e aprendizagem nas aulas de Matemática.

\section{0 estágio supervisionado e as aprendizagens profissionais no ensino da Matemática}

Nos cursos de licenciatura em Matemática, o estágio supervisionado é um dos espaços formativos privilegiados de articulação entre teoria e prática na relação do trabalho realizado na universidade e na escola, promovendo momentos de reflexões entre os estudantes acerca da autonomia, responsabilidade e compromisso político e social da profissão docente. Assim, o estágio se constitui como ambiente rico para a constituição da identidade profissional do professor que ensina Matemática na Educação Básica.

O estudante em formação inicial, ao vivenciar o processo de estágio supervisionado no âmbito das instituições escolares, pode ser um 
interlocutor no momento de pesquisar as vivências do professor da escola e estudar as relações estabelecidas no encontro/confronto pelos professores da universidade Diante disso, as trocas entre os professores da escola e da universidade poderão subsidiar a construção de novos saberes, além de aproximar os futuros professores das atividades profissionais, (...) o estágio preocupa-se não só em observar, mas também em problematizar, investigar e analisar a realidade escolar. (ALMEIDA e PIMETNA, 2015, p. 136-137).

A presença do estudante de licenciatura na escola, além da função de estagiário, ele atua como pesquisador (em formação) das relações e fenômenos educacionais que emergem na Educação Básica. Nessa função de pesquisador, as experiências vividas pelo licenciando contribuem com os processos de ensino e aprendizagem da Matemática no Ensino Superior, em especial, nos cursos de formação de professores. Os diálogos promovidos nessa trajetória formativa provocam discussões sobre as problemáticas do ambiente escolar, lócus de atuação profissional dos professores, bem como a articulação entre teoria e prática pelo trabalho educativo realizado na parceria escola-universidade, favorecendo, assim, a produção de novos saberes e estimulando espaços de formação continuada tanto para os professores formadores do Ensino Superior como da Educação Básica.

Os dados da investigação anunciam a relevância do estágio supervisionado como esse ambiente de formação inicial e continuada. No primeiro caso, as informações constantes dos protocolos (item dúvidas e questionamentos) do estagiário eram objeto de estudos, análises e reflexões em encontros realizados, semanalmente, na Universidade. As situações da realidade da escola eram contextualizadas a partir de pressupostos teóricos e metodológicos que tratam da docência na Educação Básica, consistindo, portanto, em um processo formativo mediado pela pesquisa a partir da articulação entre Universidade e Educação Básica.

Nessa dinâmica de articulação entre a escola e a universidade, colocou como primeira experiência do estagiário a escola dos anos finais do Ensino Fundamental, etapa de maior concentração das aulas expositivas. Fato que provocou muitas dúvidas e questionamentos epistemológicos e metodológicos para entender e explicar os motivos pelos quais os estudantes não participavam das aulas de Matemática.

O que podemos fazer, na condição de professor, para conquistar a atenção do aluno quando estamos explicando um assunto? Como evitar que eles se distraiam durante a aula? Como fazer o aluno se envolver? Por que na aula seguinte, os alunos não se lembram mais do que estudaram na aula anterior? Por que eles apresentam dificuldade de aprendizagem e de concentração? (ESTRATO DO PROTOCOLO DO ESTAGIÁRIO, 2018).

Os questionamentos do estagiário sinalizam aspectos importantes relativos à docência. Primeiro, algo muito comum aos que iniciam o magistério é a procura de respostas sobre o "como fazer", geralmente vinculado ao trabalho docente no âmbito do ato pedagógico. Em nossa percepção, nesse fenômeno há uma inclinação do estagiário que se encontra em atividade de iniciação à docência, em buscar alternativas imediatas às situações que, em sala de aula, limitam a constituição de uma relação pedagógica no trabalho da escola. Esse sentimento é resultante das vivências nos dois lócus de formação: a universidade e a escola. As aprendizagens nesses lugares são mediadas pelo estágio supervisionado, como campo de problematização mobilizado pela indissociabilidade entre as atividades de ensino, pesquisa e extensão. Essas experiências formativas resultam na produção de consciência 
política da profissão docente, estimulando o estudante de licenciatura a agir nas situações escolares a partir da articulação entre as discussões teóricas e epistemológicas e a realidade social da educação escolar e seus profissionais.

No segundo ponto, reconhecemos que esse exercício formativo é propiciado pelo estágio supervisionado que, ao longo do seu percurso, possibilita ao licenciando compreender a complexidade do trabalho da escola a partir dos alunos, de sua realidade social e da profissionalização docente. Nesse itinerário, observamos que o estagiário, no início de suas atividades na escola de Ensino Fundamental, manifestava preocupações de natureza metodológica, enquanto nas experiências no Ensino Médio, suas perguntas se voltaram para questões de caráter epistemológico. Ou seja, ele se deslocou do lugar que perguntava à universidade ou à escola sobre o "como fazer" para outro diferente, aquele que criou aproximação entre as duas instituições (escola e universidade), para juntas produzirem estudos e experiências atuando nestes fenômenos educativos.

Estas experiências vivenciadas no estágio supervisionado de um curso de licenciatura qualificam o entendimento da Matemática como uma ciência humana e viva, como defendido por pesquisadores da Educação Matemática (FIORENTINI; LORENZATO, 2012; D'AMBROSIO, 2016) e recomendado em documentos oficiais de orientação curricular.

\section{Reflexões finais}

A análise das dinâmicas de aulas de Matemática como processos de ensino e de aprendizagem no Ensino Fundamental e no Ensino Médio apresentadas neste artigo, abordou uma experiência de estágio supervisionado em Matemática realizado em duas escolas públicas de um município do Oeste da Bahia.

As aulas de Matemática observadas indicaram que, na maioria das vezes, as formas pelas quais os campos do conhecimento matemático têm sido trabalhados nos processos de ensino, inviabilizam a constituição de uma relação pedagógica e, por sua vez, comprometem a aprendizagem dos alunos. Isso pode ser verificado nas aulas expositivas de Álgebra e de Estatística tanto no Ensino Fundamental com no Ensino Médio. Dizemos isso porque estão sendo abordados conteúdos matemáticos de forma fragmentada e pontual, sem articulação teórica e metodológica entre eles. No caso dos Números, notamos que esse campo foi trabalhado por meio de interações e diálogos que possibilitaram maior participação dos alunos nos processos de ensino e aprendizagem. Com base nos dados, evidenciamos que essa abordagem metodológica no ensino dos Números se mostrou eficiente para atenuar tensões provocadas pelas rupturas na transição do Ensino Fundamental para o Ensino Médio.

A incidência das aulas expositivas no ensino de Matemática nos faz refletir uma questão importante: se, no começo de cada etapa, as experiências escolares nos processos de ensino e aprendizagem do conhecimento matemático, evidenciam uma relação pedagógica produzida por alunos entusiasmados que traduzem suas realidades sociais para uma linguagem numérica, por que ao longo dos anos da trajetória formativa essa relação se perde?

$\mathrm{Na}$ busca desse entendimento, o estágio supervisionado consiste em espaço significativo de formação inicial de professores e de atualização profissional para quem ensina Matemática na Educação Básica. Ele permite ressignificar os processos de ensino e aprendizagem sob o ponto de vista de seus alunos e professores. Nesse cenário, encontra-se - licenciando em Matemática, cujas experiências de aprendizagem revelaram que a metodologia de ensino é consequente de um conjunto de conhecimentos produzidos na 
articulação entre a universidade e escola. Essa produção se faz a partir do reconhecimento plural da visão de mundo, de sociedade, de educação escolar, de aluno/estudante e suas realidades sociais, inclusive, da Matemática como ciência humana e viva que mobilizada os processos de ensino e aprendizagem por meio de buscas, trocas e partilhas. Assim, alunos/estudantes e professores são sujeitos histórico-culturais que integram o trabalho escolar como atores principais da relação pedagógica no ato de conhecer a Matemática.

\section{Referências}

ALMEIDA, Jadilson. Ramos. Álgebra Escolar na contemporaneidade: uma discussão necessária. Em Teia - Revista de Educação Matemática e Tecnológica Iberoamericana, v. 8, p. 1-18, 2017.

ALMEIDA, Maria Isabel de; Selma Garrido PIMENTA (Orgs). Estágios supervisionados na formação docente. São Paulo: Cortez, 2015.

BARDIN, Laurence. Análise de conteúdo. (Trad. Luís Antero Reto e Augusto Pinheiro). Lisboa: Edições 70, 2010.

BORBA, Marcelo de Carvalho.; ARAÚJO, Jussara de Loiola. (Org.). Pesquisa Qualitativa em Educação Matemática. 3.ed. Belo Horizonte: Autêntica, 2010.

CAMARA DOS SANTOS, M. Algumas concepções sobre o ensino e a aprendizagem em matemática. Educação Matemática em Revista, São Paulo, p. 38-46, 2002.

CYRINO, M.C.C.T.. Identidade Profissional de (futuros) Professores que Ensinam Matemática. Perspectivas da Educação Matemática, v. 10, p. 699-712, 2017.

D’AMBROSIO, Ubiratan. Educação Matemática: da Teoria à Prática. 23.ed. Campinas: Papirus Editora, 2016.

DAVIDOV, Vasily. La enseñanza escolar y el desarollo psíquico. Moscú: Editorial Progreso, 1988.

FIORENTINI, Dario; LORENZATO, Sérgio. Investigação em Educação Matemática. Campinas: Autores Associados, 2012.

FREIRE, Paulo. Conscientização: Teoria e prática da libertação: uma introdução ao pensamento de Paulo Freire. São Paulo: Cortez e Moraes, 1979.

FREIRE, Paulo. Pedagogia da Autonomia: saberes necessários à prática educativa. 20.ed. São Paulo: Paz e Terra, 2001.

GIL, Antônio Carlos. Métodos e técnicas de pesquisa social. 6.ed. São Paulo: Editora Atlas, 2008.

LARCHERT, J. M. O estudo de caso do tipo etnográfico na pesquisa em educação. In: MORORÓ, L. P.; COUTO, M. E. S.; ASSIS, R. A. M. (orgs). Notas teórico-metodológicas de pesquisas em educação: concepções e trajetórias [online]. Ilhéus, BA: EDITUS, 2017, pp. 123-141. ISBN: 978-85-7455-493-8. Available from: doi: 10.7476/9788574554938.006. Also available in ePUB from: http://books.scielo.org/id/yjxdq/epub/mororo-9788574554938.epub. 
LIMA BORBA, Valéria Maria de; PEREIRA DA COSTA, André. Sucesso e fracasso no ensino da Matemática: o que dizem futuros professores de uma IES?. Revista Brasileira de Educação em Ciências e Educação Matemática, Cascavel, v. 2, n. 1, p. 55-76, maio 2018.

PIMENTA, Selma Garrido; LIMA, Maria do Socorro Lucena. Estágio e Docência. 6.ed. São Paulo: Cortez, 2010.

RIOS, Terezinha Azerêdo. A dimensão ética da aula ou o Que Nós Fazemos com Eles. In: VEIGA, Ilma P. A. (org.) Aula: gênese, dimensões, princípios e práticas. Campinas: Papirus, 2008, pp. 73-93.

RIOS, Terezinha. A. A dimensão ética da avaliação. Pro-Posições, vol. 9, no 3, p. 94-101, 1998.

VIGOTSKI, Luria S. A formação social da mente. 7.ed. São Paulo: Martins Fontes, 2007.

VIGOTSKI, Luria S.; LEONTIEV, Alexei N.; LURIA, Alexander R. Linguagem, desenvolvimento e aprendizagem. São Paulo: Ícone, 2001. 